\title{
DERECHO URBANÍSTICO Y EXCLUSIÓN SOCIAL
}

\author{
URBAN LAW AND SOCIAL EXCLUSION
}

\author{
Diego Gil Mc CaWley* \\ Nicolás Bucarey ILABACA*
}

\begin{abstract}
RESUMEN: Este artículo explora la relación entre el derecho urbanístico y procesos de exclusión social, a través del análisis de tres conflictos urbanos recientemente producidos a propósito del intento de construir viviendas sociales en comunas de altos y medianos ingresos en Santiago, Chile. Los casos descritos dan cuenta de algunos aspectos de la práctica del derecho urbanístico que constituyen fuertes obstáculos para la promoción de viviendas sociales en barrios bien localizados. El artículo sugiere que el derecho urbanístico chileno no cuenta con herramientas suficientes para contrarrestar procesos de exclusión social urbana en favor del interés público que representa la generación de viviendas sociales adecuadamente integradas en la ciudad.
\end{abstract}

Palabras claves: derecho urbanístico, segregación urbana, vivienda social.

ABSTRACT: This article explores the relationship between urban law and processes of social exclusion, through the analysis of three recent urban conflicts occurred because of the attempt to construct low-income housing units in high and middle-income districts in Santiago, Chile. The cases described show some aspects of the practice of urban law that constitute strong obstacles for the promotion of low-income housing in well-located neighborhoods. The article suggests that Chile's urban law does not have sufficient tools to counteract processes of urban social exclusion in favor of the public interest represented by the generation low-income housing adequately integrated in the city.

Keywords: urban law, urban segregation, affordable housing.

\section{INTRODUCCIÓN}

La segregación residencial socioeconómica es ampliamente reconocida como uno de los principales problemas de la vida urbana en Chile ${ }^{1}$. En la mayoría de las ciudades del país, criterios socioeconómicos inciden significativamente en cómo las personas se ubican geográficamente. Así, existen barrios con alta concentración de familias de altos ingresos,

\footnotetext{
Doctor en Derecho, Universidad de Stanford; Profesor Asistente de la Escuela de Gobierno de la Pontificia Universidad Católica de Chile; Dirección postal: Avda. Vicuña Mackenna 4860 - Edificio Mide, piso 3 - Macul, Santiago. Dirección electrónica: diego.gil@uc.cl.

** Abogado, Pontificia Universidad Católica de Chile. Abogado Seremi Minvu RM; Dirección postal: Av. Libertador Bernardo O’Higgins 874, piso 8, Santiago, 8330097. Dirección electrónica: nibucare@uc.cl.

Agradecemos los comentarios recibidos en el I Congreso de Derecho y Sociedad realizado en la Universidad Adolfo Ibáñez, sede Viña del Mar, en agosto de 2018, y en el Seminario de Derecho Administrativo de la Universidad de Chile dirigido por el Profesor José Miguel Valdivia. Guillermo Jiménez y Jaime Phillips nos hicieron llegar agudas observaciones sobre una versión preliminar del artículo. Esta investigación se enmarca dentro del proyecto FONDECYT de iniciación No 11180489, del cual Diego Gil es el investigador responsable.

1 Ministerio de Vivienda y Urbanismo (2014) p. 23.
} 
otros predominantemente habitados por individuos de clase media, y otros donde la gran mayoría de los residentes viven en situación de pobreza y vulnerabilidad ${ }^{2}$. En la medida en que el barrio en el que un individuo vive afecta significativamente sus oportunidades de desarrollo ${ }^{3}$, el hecho de que miles de familias de bajos ingresos vivan en zonas socialmente homogéneas, ubicadas en la periferia de las ciudades chilenas, con inadecuada provisión de servicios públicos y privados, constituye un problema relevante para el derecho y las políticas públicas.

La segregación social urbana es, en parte, el resultado de las preferencias habitacionales de las personas expresadas dentro de las dinámicas del mercado urbano. Sin embargo, la segregación también tiene un importante componente institucional. El derecho y las políticas públicas influyen significativamente en las preferencias que expresan los individuos por dónde y cómo habitar la ciudad. Las dinámicas del mercado habitacional se producen en el contexto de un marco y una práctica regulatoria que inciden en los procesos de desarrollo urbano y producción de viviendas.

El objetivo de este artículo es examinar la relación entre el derecho urbanístico y los procesos de exclusión social que se producen en zonas urbanas. El derecho urbanístico se refiere a los principios y reglas jurídicas cuyo objetivo es la organización racional del espacio urbano. La pregunta que motiva este trabajo es si, y cómo, el derecho urbanístico puede constituir un obstáculo para la inclusión de viviendas sociales en barrios bien localizados en la ciudad. Para responder esa pregunta, este artículo adopta una perspectiva socio-jurídica ${ }^{4}$. Para ello, contrasta el marco normativo y los instrumentos propios del derecho urbanístico - de acuerdo a cómo están regulados "en los textos" - con la práctica concreta de esta área del derecho. Para analizar la práctica del derecho urbanístico describimos y comparamos tres conflictos urbanos recientes que se han producido en Santiago con motivo del intento de construir viviendas sociales en comunas de ingresos medios y altos.

Uno de los principales argumentos que desarrollamos en este artículo es que el derecho urbanístico desencadena una práctica institucional en la cual se pueden generar fuertes obstáculos para la instalación de viviendas sociales en barrios bien localizados. Esa práctica institucional es fuertemente influenciada por propietarios y residentes con alto capital social. Como buena parte de las potestades urbanísticas recaen sobre autoridades locales, estas pueden ser ejercidas para obstaculizar la generación de viviendas sociales si la influencia de propietarios y residentes triunfa sobre el interés público. En consecuencia, debido a su posición institucional, los gobiernos locales tienen fuertes incentivos a oponerse a la llegada de viviendas sociales, a diferencia del gobierno central, quien en el derecho chileno tiene la posibilidad de velar por el interés de la ciudad como un todo. Incluso en casos en los cuales las autoridades locales no se oponen a la llegada de viviendas sociales, propietarios y residentes pueden utilizar otros mecanismos jurídicos para bloquear la llegada de grupos

\footnotetext{
2 Algunos trabajos que han intentado caracterizar las desigualdades territoriales de las zonas urbanas chilenas son Sabatini et al. (2001), EcheÑique y Urzúa (2013), Agostini et al. (2016).

3 Una amplia literatura económica y sociológica ha demostrado la importancia del barrio como un factor diferenciado en las oportunidades de desarrollo de una persona. Ver, por ejemplo, SAMPSON (2012), MASSEY et al. (2013) y CHeTTY et al. (2016).

4 Véase Friedman (1986).
} 
de bajos ingresos a sus barrios. A pesar de algunas reformas legales recientes, el derecho urbanístico chileno no cuenta con mecanismos jurídicos suficientes para contrarrestar esas dinámicas políticas en favor del interés público que representa la generación de viviendas sociales bien localizadas.

Una de las contribuciones centrales de este trabajo es enfatizar la importancia del diseño y práctica del derecho urbanístico en las dinámicas de exclusión social que se producen en las ciudades. Los problemas de segregación urbana han sido asociados principalmente a la política habitacional implementada en las últimas décadas en Chile, que ha incentivado, a través de subsidios habitacionales a la oferta y a la demanda, la producción privada de condominios de viviendas sociales con alta densidad construidos en suelo barato, ubicado principalmente en la periferia de las ciudades del país ${ }^{5}$. En años recientes, se han implementado programas especiales de subsidios que intentan promover la integración social urbana en las ciudades del país, con resultados que aún requieren evaluación ${ }^{6}$. Sin embargo, como intentamos argumentar en este artículo, la segregación urbana también tiene que ver con las reglas que definen el uso del suelo urbano y con cómo los principales operadores jurídicos implementan esas reglas. En ese sentido, el artículo propone ampliar la mirada respecto de los factores que inciden en los niveles de exclusión social que presentan nuestras ciudades, la que no solo se relaciona con los instrumentos de financiamiento que el gobierno central emplea para promover el acceso a la vivienda de grupos de bajos ingresos, sino también con las reglas y los procesos institucionales a través de los cuales se definen los usos del suelo urbano y la organización del crecimiento de las ciudades.

El artículo se desarrolla de la siguiente forma. En la segunda sección describimos el marco normativo del derecho urbanístico chileno y los principales instrumentos que autoridades públicas pueden utilizar para orientar el desarrollo urbano en el país. En la tercera sección revisamos investigaciones relevantes de los Estados Unidos que explican como el derecho urbanístico incide en procesos de segregación urbana. En la cuarta y quinta sección, que constituyen el núcleo de este trabajo, describimos y analizamos tres conflictos urbanos producidos recientemente a propósito del intento de construir viviendas sociales en comunas de ingresos medios y altos. En la quinta sección concluimos.

\section{EL DERECHO URBANÍSTICO CHILENO “EN LOS TEXTOS"}

Chile es hoy un país esencialmente urbano. Alrededor del $90 \%$ de los habitantes del país viven en zonas urbanas, lo que es una tasa comparable a la de países desarrollados como Japón, Francia y Estados Unidos ${ }^{7}$. La población urbana se concentra en un número reducido de ciudades. En Santiago vive cerca del $40 \%$ de la población del país ${ }^{8}$. 2 de cada 3 habitantes viven en Santiago, Valparaíso y Concepción, las 3 ciudades más grandes?

\footnotetext{
5 Ver, por ejemplo, GiL (2019).

6 Ver Decreto No 116 de 2015 y Decreto No 19 de 2016, Ministerio de Vivienda y Urbanismo.

OECD (2013) p. 41

8 Véase en OECD (2013).

9 Véase en OECD (2013).
} 
No es extraño que, dada las características de la vida contemporánea y las externalidades positivas que puede generar, las personas tiendan a concentrarse en zonas urbanas ${ }^{10}$. En general, las ciudades generan menores costos de transporte de bienes, permiten a los individuos participar en mercados laborales diversos y con mayores grados de especialización, y producen redes de información a través de las cuales individuos y organizaciones aprenden de otros debido a las interacciones que inevitablemente se producen en zonas urbanas densas ${ }^{11}$.

La predominancia de la vida urbana hace particularmente importante examinar las características y funcionamiento del derecho urbanístico chileno, ámbito en el cual no existe una extensa literatura académica en el país ${ }^{12}$. El derecho urbanístico se refiere a las reglas jurídicas que organizan el desarrollo físico de las ciudades. El objeto de su regulación son las técnicas de intervención de autoridades públicas en el espacio urbano ${ }^{13}$. El contenido exacto del derecho urbanístico, sin embargo, no es fácil de definir, debido a su asociación con un grupo heterogéneo de normas y actos que tienen incidencia en el proceso de desarrollo urbano.

El marco normativo del derecho urbanístico lo componen normas constitucionales, legales y reglamentarias. La Constitución establece un conjunto de normas que influyen en el ejercicio de las potestades públicas urbanísticas ${ }^{14}$. El artículo 3, por ejemplo, establece un mandato para que el desarrollo territorial sea equitativo en Chile a nivel de regiones, provincias y comunas. Otra norma importante es el artículo 19 No 24, que otorga protección constitucional al derecho de propiedad, pero que permite que la ley establezca limitaciones y obligaciones a este derecho en la medida que se justifique por la función social que la propiedad cumple. En el artículo 115 se reafirma el principio de un desarrollo territorial equitativo al interior del país, mientras que en los artículos 118 y siguientes se establecen algunas normas sobre la administración comunal, que el texto constitucional encarga a las municipalidades. Estas son instituciones claves en el derecho urbanístico en tanto buena parte de las normas que regulan el desarrollo de las zonas urbanas son dictadas a través de las potestades normativas de las municipalidades. Por su parte, el artículo 123 reconoce la necesidad de coordinación entre los municipios, y también entre ellos y los demás servicios públicos, asumiendo que hay algunos aspectos del desarrollo urbano que requieren de una mirada de la ciudad como un todo más que una fragmentada en distintas municipalidades.

Ahora bien, el grueso de las normas que regulan el ejercicio de la intervención pública en las ciudades se encuentra contenido en cuerpos legales dictados a través de la potestad legislativa, principalmente la Ley General de Urbanismo y Construcción (LGUC), que fue

\footnotetext{
10 La teoría de la aglomeración económica asociada a los economistas E. Glaeser, P. Krugman, R. Lucas y P. Romer parte de la premisa que las decisiones respecto de la ubicación geográfica de los individuos son, al menos en parte, racionales. Para una síntesis de esa literatura y un análisis de sus implicancias para la regulación urbana ver SCHLEICHER (2010).

11 SChleicher (2010) pp. 1515-1529.

12 Recientemente el derecho urbanístico ha generado mayor atención académica en la doctrina nacional. La mayoría de los trabajos constituyen esfuerzos por delinear los contornos de esta área del derecho. Ver, por ejemplo, Rajevic (2000), Cordero (2015), CORDERO (2017).

13 Ver Rajevic (2000) p. 531, y Cordero (2015) p. 104. A la misma conclusión llegan autores de tradiciones jurídicas similares, como la española. Ver CarCeller (1992) p. 18, y Ponce (2002) p. 26.

14 Ver artículo 3 y artículo 19 No 24.
} 
establecida en virtud de facultades legislativas delegadas por un Decreto Ley durante la dictadura, y cuyo texto fue fijado por el Decreto Supremo No 458 el año 1976. Ese texto recoge normas que habían sido establecidas en cuerpos legales anteriores y desde entonces ha sido modificado en numerosas ocasiones ${ }^{15}$.

El marco normativo del derecho urbanístico también lo componen reglas establecidas a través de la potestad reglamentaria. La más relevante es la Ordenanza General de la Ley General de Urbanismo y Construcciones (OGUC), establecida a través del Decreto No 47 del Ministerio de Vivienda y Urbanismo (MINVU) que también ha sido objeto de numerosas reformas. El rol de la OGUC - como toda norma emanada de la potestad reglamentaria de ejecución- es implementar las normas generales establecidas en la LGUC. Por su parte, el MINVU también dicta circulares que instruyen sobre la aplicación de las reglas de la Ley General y la Ordenanza.

El marco normativo del derecho urbanístico regula un conjunto de instrumentos de intervención pública en el espacio urbano ${ }^{16}$. El instrumento por antonomasia es la planificación urbanística, que se refiere a los planes que distintas autoridades pueden elaborar para guiar el desarrollo de una determinada zona urbana (LGUC, artículo 27). La LGUC reconoce tres niveles en los cuales opera la planificación urbanística: nacional, intercomunal y comunal (LGUC, artículo 28). A nivel nacional nunca ha existido un plan urbanístico propiamente tal. Lo que ha existido son políticas nacionales de desarrollo urbano, que establecen objetivos generales que debieran guiar el diseño e implementación de políticas y programas en el ámbito urbanístico ${ }^{17}$. Los planes reguladores intercomunales son instrumentos que regulan el desarrollo físico de unidades urbanas que comprenden más de una comuna (LGUC, artículo 34). Se denominan metropolitanos cuando el grupo de comunas que regulan representa un área metropolitana. Por su parte, los planes reguladores comunales son instrumentos que organizan el desarrollo del espacio urbano correspondiente a una municipalidad (LGUC, artículo 41).

Los planes urbanísticos, especialmente los planes reguladores intercomunales y comunales en el sistema jurídico chileno, contienen lo que la doctrina llama "régimen del suelo", que se refiere a las normas que definen los usos del suelo urbano, estableciendo derechos y deberes para los propietarios de ese suelo. El mecanismo típico a través del cual se establece el régimen del suelo es la zonificación urbana. Esta consiste en reglas que dividen el espacio urbano en distintas zonas a las que se les asignan usos que definen el tipo de construcción que se puede hacer en esa respectiva zona.

Los planes urbanísticos y las reglas contenidas en el régimen del suelo establecen directrices, obligaciones y derechos que buscan incidir en el proceso de desarrollo de una ciudad, pero la materialización de estas normas depende de la gestión que se realice por los sujetos destinatarios de esas normas. En el caso del derecho chileno, una buena parte de la gestión urbana la realizan actores privados. Estos son quienes, en la práctica, bajo la lógica

\footnotetext{
15 Rajevic (2000) p. 542.

16 Cordero (2015) pp. 109-116.

17 La última política nacional de desarrollo urbano fue publicada el año 2014, a partir del trabajo de una Comisión Asesora Presidencial que fue nombrada en 2012. Véase Ministerio de Vivienda y Urbanismo (2014).
} 
del mercado y dentro de las restricciones que imponen las reglas del derecho urbanístico, definen el desarrollo físico de una ciudad. Algunos organismos públicos, sin embargo, tienen potestades para llevar a cabo procesos que materializan las normas y directrices de los planes urbanísticos. Los organismos principales son los Servicios Regionales de Vivienda y Urbanización (SERVIU), que corresponden a servicios públicos descentralizados cuya principal labor es la construcción de viviendas sociales y obras comunitarias ${ }^{18}$. En la mayoría de los casos, sin embargo, los SERVIU no construyen directamente viviendas sociales, sino que se encargan de asignar y pagar subsidios habitacionales a personas beneficiarias, y de supervisar el adecuado cumplimiento de las obligaciones de las organizaciones y empresas que construyen con el financiamiento de los subsidios.

El derecho urbanístico también confiere potestades a determinados órganos para autorizar la construcción de obras en la ciudad y fiscalizar el cumplimiento de las normas establecidas en los planes.

El marco normativo y los instrumentos descritos en los párrafos anteriores son aquellos tradicionalmente identificados como objeto del derecho urbanístico. Sin embargo, existen varias otras entidades administrativas que tienen potestades para establecer normas o para realizar actos que tienen incidencia en la organización y fisonomía del espacio urbano $^{19}$. Lucas Sierra, en un trabajo publicado en el año 2006, identifica 19 órganos administrativos que juegan algún tipo de rol en la regulación urbana, lo que revela el grado de complejidad de esta área del derecho ${ }^{20}$.

A lo anterior hay que agregar que en el funcionamiento del derecho urbanístico existen amplios espacios para la intervención de actores privados. Enrique Rajevic ha descrito recientemente los ámbitos en los cuales actores privados ejercen funciones públicas en vivienda y urbanismo ${ }^{21}$. La planificación urbanística es una potestad que en general está reservada a organismos públicos, sin embargo, en algunos casos muy excepcionales se ha admitido la participación privada en la preparación de algunos planes específicos ${ }^{22}$. Asimismo, existen varias figuras establecidas por la LGUC en las cuales actores privados intervienen en el proceso de autorización y control de los usos urbanísticos ${ }^{23}$. Finalmente, y como señalamos anteriormente, la gestión urbana es delegada casi en su totalidad al sector privado de acuerdo al derecho vigente. La construcción de viviendas sociales, por ejemplo, que a mediados del siglo XX era una actividad llevada a cabo por corporaciones habitacionales públicas hoy se ejecuta mayoritariamente por el sector privado con y sin fines de lucro ${ }^{24}$.

El objetivo de esta investigación es explorar el impacto distributivo del derecho urbanístico, es decir, cómo este sistema regulatorio puede incidir en la distribución geográfica de las viviendas sociales en el entramado urbano. La siguiente sección utiliza la literatura comparada para ilustrar cómo este sistema normativo puede generar procesos de exclusión social.

18 Ver artículo 27, DL 1305.

19 Sierra (2006) pp. 311-321.

20 Sierra (2006) p. 320.

21 RAJEVIC (2013) pp. 221-255.

22 RajeVIC (2013) pp. 231-234.

23 Rajevic (2013) pp. 236-246.

24 Rajevic (2013) pp. 246-250. 


\section{EL IMPACTO SOCIAL DEL DERECHO URBANÍSTICO}

El derecho urbanístico dice relación con normas e instrumentos de intervención pública que inciden directamente en el desarrollo físico de una ciudad. Es decir, se trata de un sistema regulatorio que determina la distribución de los distintos usos del espacio urbano, las posibilidades de construcción, la densidad y altura de una ciudad, entre otros parámetros. Es por ello que el derecho urbanístico tiene un impacto social muy significativo. Las normas y actos que componen el derecho urbanístico inciden en el tipo de relaciones económicas y sociales de quienes habitan un asentamiento urbano.

En este trabajo nos concentramos en un tipo de impacto social del derecho urbanístico, que tiene que ver con la distribución territorial de los residentes de una ciudad. El derecho urbanístico al definir usos, alturas, densidades, entre otros estándares, influye en cómo los individuos se localizan en una ciudad, determinando en forma relevante las preferencias habitacionales de quienes viven o quieren vivir en una ciudad.

El derecho urbanístico puede influir en la distribución territorial de las personas en una ciudad generando procesos de segregación urbana que ocurren cuando grupos sociales viven separados unos de otros en distintas zonas de una ciudad. La segregación urbana socioeconómica, que es el patrón típicamente latinoamericano, se refiere normalmente a la aglomeración de familias desfavorecidas en determinadas zonas urbanas, en barrios que se encuentran separados territorialmente de familias de mayores ingresos y con inadecuada provisión de servicios públicos y privados. La literatura ha demostrado que la segregación urbana de personas de bajos ingresos o pertenecientes a minorías étnicas tiene un efecto negativo sobre las oportunidades de desarrollo de esos individuos ${ }^{25}$.

¿Cómo el derecho urbanístico puede incidir en procesos de segregación urbana? Esta es una pregunta que ha sido escasamente tratada en la literatura nacional ${ }^{26}$. En el derecho comparado, sin embargo, esta pregunta ha recibido bastante más atención. Para lo que sigue de esta sección nos centraremos fundamentalmente en la literatura académica de los Estados Unidos, país donde el vínculo entre regulación urbana y segregación social ha sido una preocupación relevante de la investigación sobre urbanismo en el derecho y otras ciencias sociales ${ }^{27}$.

Varios autores en los Estados Unidos han argumentado que el derecho y la política urbana han favorecido procesos de segregación urbana de familias desaventajadas ${ }^{28}$. A nivel federal, por ejemplo, políticas de financiamiento de infraestructura pública -como carreteras- y de incentivos a la adquisición de propiedades estimularon la creación de pe-

\footnotetext{
${ }_{25}$ Dos trabajos muy citados en la literatura que examinan el impacto de la segregación urbana en familias afroamericanas de bajos ingresos en las ciudades de los Estados Unidos son WiLSON (1987) y MASSEY y DENTON (1993). Algunos trabajos que han intentado analizar los efectos de la segregación urbana socioeconómica en Chile son Larrañaga y Sanhueza (2007), Sierralta (2008) y Sabatini y Wormald (2013).

${ }^{26}$ Con la excepción de algunos trabajos de Enrique Rajevic. Ver, por ejemplo, RAJEVIC (2010a) y RAJEVIC (2010b).

27 Ver, por ejemplo, Ford (1994), Cashin (1999), Frug (2001), SChuck (2003), BeEn (2005).

28 Aquí nos basamos fundamentalmente en el trabajo de FrUg (2001) pp. 115-164. Ver también MasSEY y DeNTON (1993) pp. 17-59.
} 
queñas ciudades (suburbios) ubicadas en la periferia de zonas metropolitanas donde residen familias de ingresos medios y altos y que exhiben alta homogeneidad social ${ }^{29}$. Por su parte, la política federal de vivienda en los Estados Unidos implementada desde fines de los años 30 hasta los años 70 es responsable de la creación de barrios altamente segregados de minorías raciales en las ciudades de ese país ${ }^{30}$. Esta política, conocida como "el programa de la vivienda pública", era financiada federalmente y operaba localmente a través de agencias locales que administraban edificios de vivienda construidos con alta densidad cuyos departamentos eran arrendados a personas de bajos ingresos. El problema con ese modelo de provisión de vivienda social era que las municipalidades incentivadas a participar eran aquellas con mayores residentes de bajos ingresos y grupos minoritarios, y su respuesta fue promover la construcción de edificios con alta densidad en barrios donde tradicionalmente se ubicaban familias desaventajadas, lo que incentivó fuertemente la segregación de esos proyectos de viviendas sociales ${ }^{31}$.

De acuerdo a Gerald Frug, las normas e instrumentos urbanísticos implementados a nivel local, es decir por municipalidades, han sido el factor jurídico y político que ha tenido mayor impacto en producir segregación urbana ${ }^{32}$. Uno de los instrumentos de mayor impacto en este sentido ha sido la zonificación y regulación del suelo urbano. Estos instrumentos han sido utilizados por muchas municipalidades, especialmente suburbios socialmente homogéneos de familias de ingresos medios y altos, para mantener sus jurisdicciones como barrios principalmente residenciales de baja densidad y altura, lo que ha tenido el efecto de prevenir la inclusión de viviendas de bajos ingresos, que tienden a construirse con alta densidad y altura ${ }^{33}$. La práctica de excluir grupos sociales a través de la potestad de zonificación urbanística es conocida como "zonificación excluyente" (exclusionary zoning).

La razón por la cual municipalidades de ingresos medios y altos utilizan sus potestades regulatorias para prevenir la inclusión de viviendas sociales tiene que ver con la presión que ejercen los propietarios sobre las autoridades de la comuna. Esa es la hipótesis conocida como la teoría del "propietario-votante" (the homevoter theory) ${ }^{34}$. En comunas residenciales de baja densidad, típicamente los suburbios en los Estados Unidos, los propietarios constituyen la mayoría del electorado de la comuna y ejercen su influencia para proteger el valor de sus residencias. Esto sucede incluso en comunas o ciudades donde los propietarios no son la fuerza electoral más grande pero igualmente ejercen mayor influencia sobre las autoridades locales en comparación con otros grupos u organizaciones debido a sus redes, nivel educacional, estatus socioeconómico, etc. ${ }^{35}$.

Las razones por las cuales los propietarios de zonas residenciales ejercen su influencia para obstaculizar la llegada de viviendas sociales son varias. Una razón tiene que ver

\footnotetext{
29 FrUG (2001) pp. 132-133.

30 Ver, por ejemplo, el trabajo de Friedman (1966) y de Schill y Wachter (1995).

31 SCHILl y WaCHTER (1995) pp. 1292-1300.

32 Frug (2001) pp. 143-149.

33 Frug (2001) pp. 143-145.

34 Ver Fischel (2001).

35 Recientemente, BEEN et al. (2014) demostraron empíricamente la importante influencia política de propietarios-votantes en el desarrollo urbano de la ciudad de Nueva York.
} 
con la percepción de que sus propiedades disminuirán su valor debido a la localización de viviendas de bajos ingresos cerca de ellas, percepción que no necesariamente se ajusta a la realidad $^{36}$. Otra razón tiene que ver con la situación fiscal de la municipalidad. La llegada de viviendas sociales puede, potencialmente, alterar el gasto público de una municipalidad, debido a que los nuevos residentes podrían requerir mayores niveles de provisión de servicios públicos. Esto podría implicar una reducción de otros servicios que benefician a los propietarios originales o la búsqueda de nuevas fuentes de financiamiento municipal. Esa alteración de la situación fiscal de una municipalidad también podría, eventualmente, tener un impacto en el valor de las propiedades de una comuna ${ }^{37}$.

Otro grupo de razones para prevenir la llegada de viviendas sociales a una comuna de mayores ingresos son de corte más sociológico o culturales. La preferencia por vivir en un barrio socialmente homogéneo se ha relacionado con cierta predisposición psicológica que las personas desarrollan durante la adolescencia y que se caracteriza por el miedo a la complejidad e incerteza de la vida social. Esto llevaría a que muchos adultos opten por vivir en un ambiente ordenado, estable y coherente ${ }^{38}$. A nivel más sociológico, la preferencia por barrios residenciales homogéneos estaría asociada a la histórica percepción social que enfatiza los aspectos negativos de la vida urbana: el ruido, el tráfico, la contaminación, el crimen, la suciedad, etc. ${ }^{39}$.

En suma, varias razones -económicas, fiscales, psicológicas, sociológicas- explicarían el uso de reglas y prácticas locales para evitar la inclusión de viviendas sociales en barrios de mayores ingresos. La siguiente sección describe esas prácticas en el contexto de tres conflictos urbanos recientes ocurridos en Santiago.

\section{EL DERECHO URBANÍSTICO CHILENO "EN LA PRÁCTICA"}

En esta sección describimos y analizamos tres conflictos urbanos recientes originados por la eventual construcción de un proyecto de viviendas sociales en barrios de medianos y altos ingresos en Santiago, Chile. El objetivo de la descripción es identificar cómo las reglas e instrumentos del derecho urbanístico pueden ser usadas con propósitos socialmente excluyentes. Esto requiere examinar el "uso" del derecho urbanístico en la práctica, es decir, como los actores principales encargados de tomar decisiones jurídicas en el ámbito urbano le dan sentido y realidad a las reglas e instrumentos de esta área del derecho.

La decisión de estudiar tres conflictos urbanos recientes tiene que ver con dos razones fundamentales. La primera dice relación con el acceso a la información. En un escenario ideal, uno quisiera estudiar todos los conflictos urbanos vinculados a la inclusión de viviendas sociales en áreas de mayores ingresos. Sin embargo, la información respecto de esos conflictos es limitada. Es por ello que hemos seleccionado conflictos que tuvieron cierta repercusión mediática. En cualquier caso, la posibilidad de ocurrencia de uno de esos conflic-

\footnotetext{
36 BeEn et al. (2014) 231-233.

37 BEEN et al. (2014) p. 232.

38 FRUG (2001) pp. 119-122.

39 Frug (2001) pp. 122-132.
} 
tos no es alta en las ciudades chilenas, porque, como bastante evidencia lo ha demostrado, el precio de los subsidios habitacionales no permite competir por suelo bien localizado, salvo casos muy excepcionales de proyectos que cuentan con financiamiento complementario, como los que se estudiarán ${ }^{40}$. La segunda razón es que el examen de tres conflictos permite estudiar con mayor profundidad los procesos institucionales que intentamos identificar en este trabajo. En otras palabras, existe un tradeoff entre, por un lado, estudiar un número limitado de casos en profundidad, y, por otro lado, estudiar un número mayor de casos pero a nivel más superficial, asumiendo la existencia de recursos limitados de investigación ${ }^{41}$. La limitación obvia de esta decisión metodológica es que las generalizaciones que uno pueda hacer con el análisis comparativo de estos casos deben tomarse con cautela.

Para el examen de los casos hemos acudido a diversas fuentes de información pública tales como reportes de prensa, información en sitios web, documentos oficiales, etc. También hemos recopilado antecedentes que no se encuentran disponibles en sitios web a través de varias solicitudes de acceso a la información pública que fueron acogidas. En ocasiones específicas hemos recolectado información acudiendo a ciertos informantes claves con conocimiento de los casos en estudio. Como algunos de estos conflictos aún no están cerrados, para este trabajo, hicimos seguimiento de estos casos hasta diciembre de 2018.

\section{Conflictos en la comuna de Peñalolén}

En la comuna de Peñalolén, ubicada en el sector sur-oriente de la ciudad de Santiago, se han producido varios conflictos urbanos motivados por la potencial construcción de proyectos de viviendas sociales en barrios de mayores ingresos.

La zona de la ciudad que hoy cubre la comuna de Peñalolén fue históricamente un área de baja densidad poblacional con un carácter cuasi rural. La población de esta área urbana comenzó a aumentar en los años 60 cuando muchas familias de bajos ingresos que vivían en otras partes de la ciudad fueron trasladas ahí, en algunos casos creando asentamientos irregulares o campamentos, que después fueron formalizados a través de distintos programas habitacionales ${ }^{42}$. El año 1981 fue creada la Municipalidad de Peñalolén para gobernar esa zona urbana, que hasta entonces era parte de la jurisdicción de la Municipalidad

\footnotetext{
40 En los últimos años la política habitacional del MINVU ha realizado esfuerzos para implementar programas de subsidios habitacionales que promuevan la integración social urbana. Dos programas recientes que tienen ese objetivo son el DS 116 (2015) y el DS 19 (2016). Estos programas establecen subsidios habitacionales para que personas con distintas realidades socioeconómicas sean incluidas en un mismo conjunto habitacional, el que debe cumplir con ciertos criterios en términos de localización y calidad de las viviendas y equipamiento. Ver Decreto No 116 de 2015 y Decreto No 19 de 2016, Ministerio de Vivienda y Urbanismo. Hasta donde llega nuestro conocimiento, no existen evaluaciones sistemáticas sobre la implementación de estos subsidios. Información anecdótica sugiere que si bien se ha producido cierto grado de integración social en los conjuntos construidos (aunque dentro de familias que califican para recibir subsidios habitacionales), la localización de estos en general no ha sido muy distinta de la de proyectos habitacionales financiados con los programas de subsidios tradicionales. Sobre la experiencia de integración social de algunos proyectos habitacionales, ver CENTRO DE POlíticas Públicas UC (2010) y Grandon y Astaburuaga (2017).

41 En el lenguaje de la metodología de las ciencias sociales, esto se conoce como el tradeoff entre maximizar validez interna versus validez externa.

42 Salcedo (2010) p. 100
} 
de Ñuñoa ${ }^{43}$. Durante los 80 , la comuna siguió siendo destino de viviendas subsidiadas para familias vulnerables. Sin embargo, en los años 90 Peñalolén comenzó a atraer el interés de residentes de mayores ingresos, debido a su cercanía con las comunas de ingresos altos ubicadas en el sector oriente de Santiago, sus precios relativamente bajos en comparación con esas comunas, y la oportunidad de vivir en desarrollos inmobiliarios de baja densidad ${ }^{44}$.

Debido al creciente interés de grupos medios y altos por vivir en la comuna, y al consiguiente aumento en el precio de los terrenos, la Municipalidad de Peñalolén ha enfrentado un escenario progresivamente complejo para promover la construcción de viviendas sociales en la comuna. La presión por acceso a vivienda formal ha sido alta en los últimos años, debido al significativo número de familias que viven como allegados o en asentamientos irregulares, y que muestran una fuerte preferencia por quedarse en esa comuna.

Una de las presiones más fuertes por acceso a la vivienda surgió desde las familias que habitaban la Toma de Peñalolén, lo que dio origen a un conflicto urbano que atrajo bastante interés público. La Toma de Peñalolén se originó el año 1999, cuando un grupo de alrededor de 1.700 familias invadió un terreno privado. El caso atrajo mucha atención porque representaba la creación de uno de los asentamientos irregulares de mayor tamaño creado varios años después del regreso a la democracia en 1990 y al final de una década de alto crecimiento económico, procesos que, en teoría, deberían desincentivar más que incentivar la aparición de estos asentamientos.

La Municipalidad de Peñalolén y el MINVU se encontraron sujetos a una fuerte presión por otorgar una solución habitacional definitiva a las familias de la Toma, las que obraron con un alto nivel de organización. Como la alternativa de trasladar a las familias de la Toma a otras comunas fue rechazada, la decisión final tomada por el MINVU fue comprar terrenos en otros lugares dentro de Peñalolén para construir las viviendas sociales requeridas.

Uno de los terrenos que el MINVU compró para proveer soluciones habitacionales a los residentes de la Toma estaba ubicado en un condominio privado de familias de altos ingresos conocido como la "Comunidad Ecológica". Eso generó una fuerte tensión entre el gobierno y los residentes de ese condominio, quienes argumentaron que el proyecto medioambiental que motivó la creación de esa comunidad habitacional se vería por completo destruido con la construcción de un proyecto de viviendas sociales de alta densidad. Después de un largo proceso de negociación, el interés de los residentes del condominio prevaleció. Una empresa inmobiliaria compró el terreno que había sido adquirido por el MINVU y entregó un monto de dinero a cada una de las familias contempladas en el proyecto habitacional subsidiado para que pudieran acceder a viviendas ubicadas en otros barrios de la comuna. Así, con ese bono adicional de dinero complementario a los subsidios habitacionales, quienes eran parte del proyecto pudieron financiar la construcción de viviendas en otra zona de la comuna.

A pesar de la solución que se otorgó a las familias de la Toma de Peñalolén, el conflicto por incluir viviendas sociales en terrenos de la Comunidad Ecológica continuó. Debido a la necesidad de construir viviendas sociales para familias de allegados de la comuna,

\footnotetext{
43 SAlCedo (2010) p. 100.

44 Salcedo (2010) pp. 100-101.
} 
la Municipalidad decidió hacer un cambio al Plan Regulador Comunal para aumentar la densidad en varias zonas y organizar mejor las reglas que gobiernan su jurisdicción. Los cambios propuestos incluían el aumento de densidad en un sector de la Comunidad Ecológica ${ }^{45}$. El alcalde de ese entonces decidió someter la modificación al Plan Regulador a un plebiscito, el cual fue realizado el 11 de diciembre de $2011^{46}$. La votación de los residentes de la comuna dio como resultado el rechazo al cambio al plan regulador por un $52 \%{ }^{47}$. La resistencia al cambio del plan regulador tuvo distintas motivaciones. Algunos dirigentes de movimientos sociales consideraron que el principal beneficiario del aumento de densidad en varias partes de la comuna iba a ser la industria inmobiliaria, lo que atentaba contra el interés público de los habitantes de ese distrito ${ }^{48}$. Otros grupos, como algunos residentes de la Comunidad Ecológica, rechazaron el cambio por sus implicancias en la potencial construcción de proyectos de viviendas sociales en zonas residenciales de baja densidad y de mayores ingresos, como las de ese sector de la comuna.

La Municipalidad de Peñalolén, junto con el MINVU, siguió buscando opciones para organizar la construcción de proyectos de viviendas sociales dentro del municipio que pudieran alojar a familias en situación de allegamiento. Para ello, el MINVU expropió un terreno ubicado en la Comunidad Ecológica. El problema del terreno es que en esa zona las normas del Plan Regulador permiten una densidad máxima de 50 habitantes por hectárea, lo que no hacía factible la construcción de un proyecto de viviendas sociales. Por ello, la Municipalidad, junto con organizar a las familias interesadas en la postulación a los subsidios y planificación del proyecto, decidió cambiar el plan regulador para aumentar la densidad de ese terreno. Así, cumpliendo con todos los procedimientos legales vigentes para realizar el cambio al plan regulador, dictó el Decreto Alcaldicio No 1200/3326 del año 2016, que aumentó la densidad de ese sector de la comuna.

Sin embargo, un propietario de la Comunidad Ecológica decidió interponer un recurso de protección para dejar sin efecto ese Decreto Alcaldicio por una supuesta infracción de los principios de probidad y veracidad administrativa, y por una supuesta amenaza cierta e inminente al derecho a vivir en un medio ambiente libre de contaminación establecido en el artículo 19 número 8 de la Constitución Política. El recurso de protección fue rechazado por la Octava Sala de la Corte de Apelaciones de Santiago, pero acogido por la Tercera Sala de la Corte Suprema ${ }^{49}$. Los argumentos principales entregados por la Corte Suprema para acoger el recurso fueron que el Decreto Alcaldicio alteraba el resultado del plebiscito comunal vinculante que se había realizado algunos años atrás que había mantenido la densidad baja de ese sector de la comuna, y que no había considerado que el aumento de la densidad alteraba los asentamientos humanos y de animales, y la flora protegida existente.

45 EMOL (11/12/2011b).

$46 \operatorname{EMOL}(11 / 12 / 2011 \mathrm{a})$.

47 EMOL (11/12/2011b).

48 Radio Uchile (12/12/2011).

49 NACIF CON MUNiCIPALIDAd PEŃALOLÉN (2018). 
Al término de la recopilación de información para este trabajo, la Municipalidad se encontraba evaluando qué acciones tomar después de la decisión de la Corte Suprema ${ }^{50}$.

\section{Conflicto en la comuna de Maipú}

El segundo caso que describiremos corresponde al conflicto urbano ocurrido a propósito de la promoción de un proyecto de viviendas sociales en la comuna de Maipú, ubicada en el sector poniente de la ciudad de Santiago. La comuna de Maipú alberga en su mayoría familias de ingresos medios.

En el año 2014 el Comité de Allegados ${ }^{51}$ "Flor del Valle" conformado por un grupo de habitantes de campamentos ubicados en las comunas de Maipú y Cerrillos de la Región Metropolitana, acudió ante las autoridades de la Municipalidad de Maipú con el objeto de obtener financiamiento complementario a los subsidios habitacionales otorgados por el MINVU para adquirir el predio ubicado en dicha comuna, en el cual se desarrollaría un proyecto de viviendas para 850 personas. Con el financiamiento de los subsidios habitaciones no era posible adquirir el terreno y cubrir los costos de la construcción del condominio de viviendas sociales.

Los fondos públicos a los que buscaban acceder provenían del "Programa Mejoramiento de Barrios”, en cuyo reglamento ${ }^{52}$ se establecen distintas vías de acción para contribuir a la reducción de las condiciones de marginalidad sanitaria con déficit de servicios básicos. Dentro de ellas se contempla la construcción de infraestructura sanitaria y la entrega de sitios con su respectivo título de propiedad a cada beneficiario. En la asignación de fondos intervienen distintos órganos públicos, dentro de los cuales la Municipalidad es la encargada de realizar estudios de diagnóstico y de promover la organización de los beneficiarios del Programa, así como también de la elaboración de los proyectos.

El Comité fue asesorado desde un comienzo por la Fundación TECHO-Chile, que en el ámbito de la organización de proyectos de viviendas sociales opera como una Entidad Patrocinante ${ }^{53}$. Gracias a las gestiones del Comité y de TECHO-Chile, el alcalde de la Municipalidad de Maipú remitió el 23 de junio de 2014 al Subsecretario de Desarrollo Regional y Administrativo de la Región Metropolitana la postulación del proyecto de Conjunto de Viviendas Económicas "Flor del Valle".

La postulación del comité "Flor del Valle" resultó seleccionada y, por tanto, se le asignó a la Municipalidad de Maipú la suma de \$492.959.236 para la adquisición del terreno en la misma comuna. Este predio cuenta con una superficie de 16.585,16 metros

50 EMOL (14/7/2018).

51 El allegamiento se define como la estrategia utilizada por los hogares y núcleos familiares para solucionar la falta de vivienda, compartiendo una vivienda con otro hogar o núcleo (ver sitio web "Observatorio Social”, MINisterio de Desarrollo Social).

52 Decreto No 829 de 1998, Ministerio del Interior.

53 Las Entidades Patrocinantes son personas naturales o jurídicas, públicas o privadas, con o sin fines de lucro, cuyas principales funciones son: asesorar individual o colectivamente a las familias en el proceso de postulación a un subsidio del MINVU, elaborar los proyectos técnicos de vivienda y/o de urbanización, prestar asesoría legal durante el desarrollo del proyecto y acompañar socialmente a las familias desde la postulación hasta el término definitivo del proyecto (ver sitio web "Proveedores Técnicos MINVU", MinisTerio DE ViVIENDA Y URBANISMO). 
cuadrados y se encuentra localizado en el límite sur de la comuna de Maipú, rodeado de viviendas de clase media y media-baja que se emplazaron en dicho lugar en la década de los 80 y 90 .

Habiendo recibido los dineros, la Municipalidad de Maipú se encontraba habilitada legal y económicamente para adquirir el terreno ubicado en la misma comuna. Sin embargo, con fecha 11 de noviembre de 2016, la Municipalidad no procedió a la adquisición del predio, sino que, por el contrario, decidió restituir los fondos asignados para ello ${ }^{54}$. Esta decisión se tomó en la Sesión Ordinaria No 1032 del Concejo Municipal de Maipú llevada a cabo el 29 de julio de 2016. En ella, los integrantes del Concejo debatieron en extenso sobre la adquisición del predio y la posterior construcción de viviendas sociales en la comuna. Finalmente, la discusión se zanjó en una votación que tuvo el siguiente resultado: 5 votos de rechazo -entre ellos, el del Alcalde-, 4 votos a favor y una abstención.

La votación de rechazo fue adoptada por autoridades de distintos partidos políticos quienes no comparten necesariamente la misma sensibilidad ideológica ${ }^{55}$. Ahora bien, dentro de las razones expresadas por quienes rechazaron adquirir el predio para la construcción del proyecto de viviendas se pueden identificar, por un lado, que no habría existido suficiente diálogo entre las partes involucradas -Fundación TECHO-Chile, el comité Flor del Valle y los habitantes del sector- y, además, que no estaban dadas las condiciones para la construcción del proyecto, ya sea porque podrían ocurrir hechos de violencia, o bien, porque el municipio sería incapaz de satisfacer las necesidades de los nuevos vecinos del sector. En cualquier caso, la decisión del Concejo Municipal en orden a rechazar la adquisición del inmueble para llevar adelante la construcción del proyecto habitacional pareció reflejar los temores de los habitantes del sector donde este se llevará a cabo respecto de sus nuevos vecinos, más que expresar razones atendibles que hubieran justificado la inviabilidad de llevarlo a cabo ${ }^{56}$.

\footnotetext{
54 A través del Decreto Alcaldicio No 4184.

55 Votaron a favor de adquirir el predio los concejales Carol Bortnick (PPD); Antonio Neme (UDI); Ariel Ramos (PC); Mauricio Ovalle (DC). Por su parte, votaron en contra el alcalde Christian Vittori (DC) y los concejales Herman Silva (DC); Carlos Jara (PPD); Abraham Donoso (DC): y Marcela Silva (PS). Se abstuvo de votar el concejal Alejandro Almendares (Ind.).

56 A modo de ejemplo de las razones entregadas, los motivos que esgrimió el concejal, don Herman Silva (DC), para justificar su voto de rechazo fueron los siguientes: “...yo recibí a las dos partes, conozco el pensamiento de uno y de otro y con ninguno de los dos bandos me he comprometido, pero ahora si lo traen al Concejo hay que tomar una resolución al respecto y yo parto con respecto a eso diciendo que en cuanto a mí se refiere y en lo que voy a exponer que me pasó a mí siendo Alcalde de la comuna y viviendo yo en el sector, también hubo algo parecido sacaron gente de las turbinas y de otros lugares del gran Santiago y yo cuando vi el asunto que era bien complejo, obtuve que el $90 \%$ de los que llegaran ahí fueran de Maipú, creí que con eso solucionaba todo el problema y no fue así el asunto, llegó, se asignaron las viviendas, había que ir de parte del Serviu hacerse cargo, un día X y un día menos pensado yo estaba en mi casa, vivía en la Villa Arturo Godoy y muy cerca donde se están construyendo y sentí un bullicio violento y alrededor de 400 pobladores de allá llegaron esperaron que se abriera una puerta y pasaron todo y coparon todo, indudablemente que cuando la cosa se puso muy peligrosa, aparecieron dos helicópteros sobre volando (sic), porque el Alcalde en el fondo estaba secuestrado y después llegaron tres buses de Carabineros, yo hablé con ellos”. “...de acuerdo a lo que me pasó a mí, ahora está mucho más grande la Villa Jardín Los Héroes que antes, tiene mucho más gente, pero no quiero pasar por lo que pasé antes y tener que dejar mi casa, irme a otro lugar por el ataque constante digamos sobre todo los días festivos o los sábados, por lo
} 
A pesar de la decisión adoptada por la Municipalidad de Maipú de rechazar los fondos y por tanto obstaculizar la construcción del proyecto de viviendas sociales, finalmente el MINVU decidió comprar directamente el predio para permitir el desarrollo del proyecto. Para ello, este órgano adquirió el inmueble por aplicación de la Ley 16.391, que en su artículo 50 habilita al MINVU para expropiar predios que se encuentren afectos a utilidad pública, tal como se consideró en este caso. Al término del levantamiento de información usada en este artículo, el proyecto se encontraba en una etapa avanzada de construcción.

\section{Conflicto en las comunas de Vitacura y Las Condes}

El tercer conflicto que describiremos ocurrió a propósito de un proyecto de viviendas sociales promovido por la Municipalidad de Las Condes para ser emplazado en un barrio ubicado dentro de la comuna de Vitacura, uno de los sectores con viviendas de mayor valor en la Región Metropolitana.

La curiosa situación en la cual una Municipalidad pretendía localizar un proyecto de viviendas sociales en otra comuna se produjo porque previo a la creación de la Municipalidad de Vitacura en 1991, el terreno donde se emplazarían las viviendas subsidiadas se encontraba dentro de los límites de la comuna de Las Condes. Ese terreno fue adquirido por la Municipalidad de Las Condes el año 1971, y ha permanecido en su patrimonio hasta el día de hoy, puesto que cuando se creó la Municipalidad de Vitacura ese predio nunca le fue transferido, a pesar de ubicarse dentro de su territorio.

En su calidad de propietario del inmueble en cuestión, la Municipalidad de Las Condes puede legítimamente usarlo y destinarlo a cualquier fin que no vaya contra la ley o derecho ajeno. Previo a una reforma al Plan Regulador Comunal de Vitacura del 23 de marzo de 2018, el terreno perteneciente a Las Condes (ubicado en Vitacura) permitía una densidad media de 200 viviendas por hectárea. En consecuencia, era perfectamente lícito para las autoridades locales de la comuna de Las Condes que se promoviera un proyecto de viviendas que cumpliera con dichos parámetros.

Así fue como a finales del mes de marzo y principios del mes de abril del año 2017, la Municipalidad de Las Condes presentó dos anteproyectos ante la Dirección de Obras de Vitacura con el propósito de construir entre 450 y 562 viviendas subsidiadas para recibir aproximadamente a 2000 residentes provenientes de la comuna de Las Condes, principalmente del sector Colón Oriente. Los habitantes de dicho sector, ubicado al suroriente de la comuna entre las calles Río Guadiana, Cristóbal Colón, Padre Hurtado y Paul Harris, sufren el estigma de ser un barrio al que se le asocia varios problemas sociales.

El primer paso para llevar a cabo un proyecto inmobiliario es la presentación de un anteproyecto de edificación ante la Dirección de Obras Municipales. Una vez aprobado por el Director de Obras Municipal, dicho acto le asegura al requirente que la normativa urbanística vigente al momento de la aprobación del anteproyecto no sufrirá cambios siempre que presente el proyecto definitivo dentro del plazo de 180 días, el que puede ampliarse a un

tanto, yo lo siento mucho, pero como sufrí algo en carne propia, no voy a aprobar digamos lo que está propuesto en este momento" (Acta de la Sesión Ordinaria No 1032 del Concejo Municipal de Maipú). 
año ${ }^{57}$. En atención a ello, la Municipalidad de Las Condes ingresó los anteproyectos mencionados arriba. Sin embargo, el Director de Obras no se pronunciaría respecto a ninguno de ellos debido a que con fecha 7 de abril de 2017 el alcalde de Vitacura dictó el Decreto 3/764 a través del cual decidió postergar por tres meses el otorgamiento de permisos de subdivisión, loteo, urbanización y de construcción en la zona donde se desarrollaría el proyecto de Las Condes. El alcalde se encontraba habilitado para tomar la decisión de postergar los permisos en base a lo dispuesto en el artículo 117 de la LGUC, dado que en el sector donde iba a emplazarse el proyecto de viviendas se había aprobado recientemente el estudio de modificación del Plan Regulador Comunal y, además, la Secretaría Regional del MINVU aprobó dicha determinación.

Por lo demás, según se deriva de las palabras que el alcalde de Vitacura, don Raúl Torrealba, entregó a los medios de prensa, aquél no estaba de acuerdo con que se realizara un proyecto de viviendas sociales en su comuna, por las siguientes razones: "El precio impide que puedan construirse viviendas sociales. La vivienda social está regulada y determinada. No se pueden hacer viviendas sociales a ese precio. Es lo que dije desde el principio" 58 . “¿Viviendas sociales? No, viviendas sociales, jamás. Y no es porque Torrealba sea insensible, es porque la ley no lo permite. No es cuestión de voluntad"59. "Me he sentado a la mesa con la mejor disposición, aplaudo a Lavín, ojalá pueda hacer muchas viviendas sociales en Las Condes. Me parece súper bien lo que hace. Cada alcalde es soberano en su comuna y Joaquín tiene que decidir qué hace en Las Condes [...] desde hace años que Vitacura está pensada como una comuna que aporta parques a la ciudad. No es que yo sea un insensible; es el proyecto que hemos impulsado desde hace años, desde el puente Lo Saldes hasta el San Francisco" 60 .

Sin perjuicio de la voluntad de las autoridades de la comuna de Vitacura de obstaculizar el proyecto de viviendas sociales en su comuna, a la fecha de presentación de los anteproyectos de construcción por parte de Las Condes en la Dirección de Obras de Vitacura, las normas de uso de suelo y edificación eran plenamente compatibles con el proyecto de viviendas que se pretendía realizar ${ }^{61}$.

Así, a través del Decreto No 3/646 de fecha 23 de marzo de 2018 se materializó la modificación del Plan Regulador Comunal de Vitacura, cambiando tanto el uso de suelo como también las condiciones de edificación de la zona donde se ubica el predio de Las Condes. En virtud de esta modificación, dicho lugar pasó de constituir un Área de Edificación Aislada Media (E-Am5) a ser un Área de Edificación Especial No 2 (Ee2), equivalente al Parque Metropolitano de Santiago. Eso implica que ahora en el terreno no se puede construir sino edificaciones compatibles con el carácter de área verde de uso público, las cuales tampoco pueden superar en su conjunto más del $1 \%$ de la superficie total del pre-

\footnotetext{
57 Ver artículo 116 inciso 90 LGUC y artículo 1.4 .11 de la OGUC.

58 El Mercurio de Santiago (6/5/2018) p. D 11.

59 El Mercurio de Santiago (6/5/2018) p. D 11.

60 El Mercurio de Santiago (6/5/2018) p. D 11.

61 De hecho, en un predio adyacente casi al mismo tiempo se aprobó un anteproyecto para construir un edificio con departamentos de alto valor económico, a través de la Resolución No 744 del Director de Obras de fecha 12 de diciembre de 2017.
} 
$\operatorname{dio}^{62}$. Con estas condiciones normativas, claramente el proyecto de viviendas sociales se hacía inviable en la zona.

Este cambio en las condiciones urbanísticas de la zona donde se encuentra emplazado el predio de Las Condes en Vitacura provocó una intensa discusión entre las autoridades de ambos Municipios. Sin embargo, con el objeto de poner fin a la controversia entre las autoridades, el gobierno central intervino en la disputa a través del Ministro de Vivienda y Urbanismo $^{63}$. Como resultado de esta intervención, el Ministro y los alcaldes de Las Condes y Vitacura suscribieron una declaración de intenciones con fecha 4 de julio de 2018 en virtud de la cual se comprometieron a lo siguiente: La Iltre. Municipalidad de las Condes "a evaluar la existencia de vías legales idóneas para transferir su propiedad a la Ilustre Municipalidad de Vitacura con un 50\% del terreno a título gratuito y el saldo a título oneroso"; mientras que la Iltre. Municipalidad de Vitacura, se comprometió a "evaluar las alternativas legales idóneas que permitan al Municipio de Las Condes a desarrollar su proyecto integrador mediante la obtención de los fondos necesarios derivados de la adquisición, a título oneroso, del $50 \%$ restante de la propiedad".

A los pocos días de suscribir el acuerdo, la Municipalidad de Las Condes hizo pública su voluntad de construir un proyecto de viviendas sociales en un predio dentro de los límites de su comuna, particularmente en el sector de la Rotonda Atenas, el cual recibirá a más de 80 familias que cumplan con los criterios definidos por el Concejo Municipal ${ }^{64}$.

\section{DISCUSIÓN DE LOS CASOS}

¿Qué lecciones pueden obtenerse de los tres casos descritos respecto de la práctica del derecho urbanístico en Chile y su incidencia en procesos de exclusión social?

Un primer aspecto que merece ser comentado tiene que ver con el resultado de los tres conflictos urbanos descritos. A primera vista podría parecer que el desenlace de estos conflictos, a pesar de todas las tensiones sociales e institucionales que han producido, no ha sido necesariamente desfavorable para la construcción de vivienda sociales. En el caso del conflicto en Maipú, el proyecto está en construcción. En Peñalolén el proyecto ya está aprobado por las autoridades locales y queda por verse su desenlace institucional después de la decisión de la Corte Suprema que acogió el recurso de protección en contra del cambio al plan regulador que permitió la aprobación del proyecto. En el conflicto entre las $\mathrm{Mu}-$ nicipalidades de Vitacura y Las Condes, la construcción en Vitacura fue cancelada, pero al parecer el proyecto sería viable en un barrio de la comuna de Las Condes. En consecuencia, después de largas y fuertes batallas, es posible que las viviendas sociales que originaron esos conflictos sean finalmente construidas.

Sin embargo, creemos que es al menos problemático sugerir que el resultado final ha sido positivo desde el punto de vista del interés público en juego: la generación de vivienda social inclusiva. Los tres casos ilustran los altos costos que la construcción de viviendas so-

\footnotetext{
${ }^{62}$ Ver Artículo 5.2.2 del Plan Regulador Metropolitano de Santiago.

63 La Tercera PM (10/4/2018).

${ }^{64} \operatorname{EMOL}(5 / 7 / 2018)$.
} 
ciales tiene que enfrentar cuando se trata de construir unidades habitacionales subsidiadas en barrios relativamente caros. Estos proyectos no solo enfrentan la barrera del precio del suelo que desde ya hace prácticamente imposible la construcción de cualquier proyecto de viviendas sociales en comunas de ingresos medios y altos, y que los programas de subsidios habitacionales, incluso en sus nuevas versiones que intentan promover la integración social, no han podido resolver. Además de esa barrera inicial, los tres casos demuestran el nivel de tensiones sociales e institucionales que se genera en los pocos casos en los que esa barrera es superada. Eso no solo es problemático desde el punto de vista de los costos de los proyectos analizados sino también desde la perspectiva de la señal que se genera para futuros proyectos. El nivel de riesgo involucrado en este tipo de proyectos constituye un fuerte desincentivo para varios de los actores públicos y privados involucrados en la construcción de vivienda sociales.

Los tres casos analizados muestran que la práctica del derecho urbanístico puede generar fuertes obstáculos para la generación de viviendas sociales bien localizadas. Aquí nos centraremos en tres aspectos principales. Un primer aspecto tiene que ver con la presión de grupos de interés, que en los tres casos descritos está representada por la influencia ejercida por los propietarios que viven en zonas aledañas a los proyectos. En comunas de ingresos medios y altos la presión de estos grupos afecta de modo relevante la práctica del derecho urbanístico. La teoría de los grupos de interés sugiere que en aquellos contextos regulatorios en los cuales los beneficios son difusos -es decir, aprovechados por muchos individuos $\mathrm{u}$ organizaciones- y los costos son concentrados -es decir, impuestos sobre pocos individuos u organizaciones- es esperable que estos últimos grupos ejerzan una fuerte influencia para que las decisiones regulatorias les sean favorables ${ }^{65}$. Los casos descritos, sin embargo, no se ajustan perfectamente al modelo tradicional de la teoría de grupos de interés, porque aquí tanto los beneficios como los costos están concentrados. Los beneficiados son las familias que habitarán las viviendas sociales y quienes deben soportar los (supuestos) costos son los propietarios aledaños, quienes, como vimos en los casos, consideran que el valor de su propiedad puede verse afectado o temen la presencia de vecinos a quienes no conocen y que pertenecen a otro estrato socioeconómico. A pesar de que en este contexto regulatorio existen dos grupos de interés opuestos, los propietarios ejercen una presión más fuerte, probablemente debido al mayor capital cultural, social y económico que poseen. Los casos demuestran que ese desbalance entre los grupos de interés directamente afectados solo se puede compensar en la medida que participen otros actores institucionales que apoyen las demandas de las familias beneficiarias de las viviendas subsidiadas.

Otro aspecto importante de la práctica urbanística descrita es que los propietarios y residentes aledaños a los proyectos de viviendas sociales ejercen fuertes presiones sobre las respectivas autoridades locales, las cuales cuentan con amplias potestades que pueden utilizar para obstaculizar la construcción de las viviendas. En el caso de Maipú, el Concejo Municipal decidió rechazar la transferencia de recursos del gobierno central para la compra del terreno requerido. En el caso de Vitacura, se hizo un cambio a las densidades establecidas por el plan regulador comunal para el terreno en cuestión, modificación que normalmente

65 Ver Baldwin et al. (2012) pp. 43-49. 
demora bastante más tiempo del que tomó en este caso. El caso de Peñalolén no ha seguido el mismo patrón en este punto, debido a que las autoridades locales han ejercido un rol activo en promover la construcción de viviendas sociales en su comuna. A pesar de ello, el interés de propietarios y residentes que se oponen a la llegada de viviendas subsidiadas para familias de bajos ingresos ha prevalecido, para lo cual han usado varios mecanismos institucionales existentes. En un primer término lograron obstaculizar la construcción de viviendas sociales a través de la movilización social que permitió el rechazo, expresado en un plebiscito comunal, al cambio del plan regulador necesario para construir esas viviendas en los terrenos de la Comunidad Ecológica. En una segunda instancia, ese mismo resultado se logró a través de la intervención de los tribunales por medio de un recurso de protección.

Lo común a estos tres casos es que la práctica del derecho urbanístico envuelve un conjunto de procesos institucionales en los que propietarios y residentes con alto capital social y económico pueden influir para defender sus intereses. Varios de estos procesos jurídicos se encuentran alojados en el nivel local, pero también existen otras instancias donde grupos de interés pueden influir sobre decisiones vinculadas al desarrollo urbano que terminan incidiendo en las posibilidades de localización de viviendas sociales, como lo demuestra el caso de Peñalolén. Es interesante notar que a diferencia del caso norteamericano, donde lo habitual es utilizar normas urbanísticas que previenen la llegada de viviendas sociales a zonas de mayores ingresos, estos casos demuestran que los procesos jurídicos para obstaculizar la llegada de viviendas sociales han sido utilizados después de que se ha hecho viable la instalación de un conjunto de viviendas sociales en un área residencial de grupos medios y altos ${ }^{66}$.

Un último aspecto relevante de comentar es la relación entre el gobierno central y los gobiernos locales. Las municipalidades tienen fuertes incentivos a favorecer el interés de sus residentes, quienes conforman el cuerpo electoral de la comuna. En consecuencia, el ejercicio de sus potestades urbanísticas tenderá a favorecer al grupo mayoritario de la comuna. Por eso, no es de extrañar que autoridades de una comuna como Vitacura se resistan a la llegada de familias de bajos ingresos. Peñalolén, por su parte, tiene presencia de distintos grupos socioeconómicos en la comuna, lo que permite que sus autoridades favorezcan la inclusión de viviendas sociales en terrenos de esa jurisdicción, especialmente para residentes de la misma comuna. Quien ejerce un rol clave en estos procesos es el gobierno central, representado por el MINVU. En los tres casos se puede ver que el MINVU ejerció un rol mediador entre los intereses de los gobiernos locales y el interés general de promover la generación de viviendas sociales. En algunos casos, su voluntad se impuso frente a la de autoridades locales. En el caso de Peñalolén y Vitacura, el MINVU medió entre las partes para buscar una solución que respetara el interés de los residentes de esas comunas pero que también permitiera la construcción de viviendas sociales en barrios cercanos. En el caso de Vitacura, sin embargo, primó el interés de esa comuna de no llevar a cabo el proyecto en el

\footnotetext{
${ }^{66}$ Habría que precisar, sin embargo, que la utilización de normas urbanísticas para prevenir la construcción de conjuntos habitacionales en densidad, y con ello obstaculizar la llegada de viviendas subsidiadas antes de que su edificación sea viable en un barrio de altos ingresos, es algo que hasta donde tenemos conocimiento no ha sido estudiado sistemáticamente en Chile.
} 
terreno original, pero con la compra de parte del terreno a Las Condes, esta última municipalidad podrá usar esos fondos para financiar el proyecto que ahora será emplazado en un sitio en esa jurisdicción, lugar con muy buena localización dentro de Santiago. En el caso de Maipú, el MINVU se impuso sobre el interés del gobierno local, expropiando directamente el terreno para construir el condominio de viviendas sociales. En el caso de Peñalolén, el MINVU apoyó a las autoridades locales expropiando un terreno de la Comunidad Ecológica, pero la Corte Suprema frenó la construcción de viviendas sociales. Pareciera, entonces, que los gobiernos locales no están en una posición institucional adecuada para proteger el interés de promover la construcción de vivienda inclusiva. Para ello se requiere de una mirada de ciudad, que en el caso del régimen jurídico chileno vigente, está ubicada en el gobierno central.

\section{CONCLUSIÓN}

El derecho urbanístico puede constituir un espacio para fuertes disputas entre ciudadanos. Como el derecho urbanístico tiene que ver con las normas que definen los derechos de propiedad que tienen los residentes de una ciudad, y con la forma física y social que las zonas urbanas adoptan, es razonable la alta sensibilidad que la intervención administrativa en el espacio urbano genera.

Los casos descritos en este trabajo dan cuenta de algunos aspectos de la práctica del derecho urbanístico que constituyen fuertes obstáculos para la promoción de viviendas sociales en barrios bien localizados. El primero es la fuerte influencia que ejercen propietarios y residentes con alto capital social sobre los tomadores de decisiones en materia urbanística. El segundo es la existencia de una amplia variedad de potestades que recaen sobre todo en las autoridades locales, las cuales pueden ser usadas para obstaculizar la generación de viviendas sociales si la influencia de propietarios y residentes triunfa sobre el interés público. El tercero es la posición institucional de los gobiernos locales, que tienen fuertes incentivos a oponerse a la llegada de viviendas sociales, a diferencia del gobierno central, quien en el derecho chileno tiene la posibilidad de velar por el interés de la ciudad como un todo. El buen gobierno de las ciudades requiere la participación de propietarios y residentes en los procesos de decisiones urbanísticas, la discrecionalidad en el uso de mecanismos de intervención para ir respondiendo a las necesidades urbanas que van surgiendo y la presencia de gobiernos locales que puedan atender las necesidades de sus comunidades. Sin embargo, esos intereses deben balancearse con el interés público que representa la generación de viviendas sociales bien localizadas, sobre todo considerando los altos niveles de segregación social urbana que presentan las ciudades chilenas. El derecho urbanístico vigente en Chile no tiene mecanismos jurídicos suficientes que permitan garantizar la satisfacción de ese interés público.

Aunque tímidamente, el derecho urbanístico chileno ha comenzado a reconocer la importancia que tiene incorporar la integración social como parte de los objetivos que deben ser atendidos por las instituciones con potestades para organizar el uso racional del espacio urbano. Algunas reformas legales recientes han incorporado en la legislación urbanística chilena herramientas para que tanto el gobierno central como las municipalidades 
puedan promover, a través de incentivos en las normas urbanísticas, el desarrollo de proyectos habitacionales con integración social ${ }^{67}$. No existe evidencia sobre la implementación de esas normas, sin embargo, y se trata de reglas que habilitan el establecimiento de incentivos más que obligaciones para que las autoridades utilicen instrumentos que favorezcan proceso de integración social en la ciudad. Un proyecto de ley reciente que se encuentra en una etapa avanzada de discusión en el Congreso incorpora el objetivo de la integración social dentro de la legislación urbanística, estableciendo obligaciones para que los instrumentos de intervención pública que regulan el uso del suelo urbano promuevan un acceso más equitativo a los bienes y servicios públicos de las ciudades ${ }^{68}$. Está por verse si el proyecto será aprobado en el Congreso y si tendrá un efecto significativo sobre la práctica del derecho urbanístico.

Existe experiencia comparada que puede servir de referencias para un reconocimiento explícito de la integración social urbana en el derecho urbanístico. Un ejemplo es la doctrina conocida como "contribución regional justa" que se ha implementado en algunos Estados de los Estados Unidos. Esta estrategia consiste en regulaciones que imponen una obligación directa a las municipalidades que conforman un área metropolitana de adoptar políticas públicas, usualmente a través de sus planes urbanísticos, para asegurar la construcción de viviendas asequibles que cumplan con una determinada cuota de las necesidades habitacionales de toda la zona metropolitana ${ }^{69}$. Así se asegura que la vivienda para sectores de bajos ingresos no se concentrará en un determinado sector de una ciudad sino que estará dispersa en los distintos barrios y distritos de todo el área urbana.

En suma, el derecho urbanístico y su práctica pueden tener un efecto importante sobre los niveles de igualdad social y económica que existen en una ciudad. El argumento central que hemos intentado proponer en este trabajo es que la segregación social urbana no es solo un problema del financiamiento disponible para proyectos habitacionales sino también tiene relación con las normas y procesos institucionales que regulan la gobernanza de nuestras ciudades.

\footnotetext{
${ }^{67}$ Ver artículo 1 inciso $8^{\circ}$ y 9o DFL No 2, 1959, Ministerio de Hacienda y artículo 184 LGUC.

68 Boletín 12288-14, Proyecto de ley que modifica diversos cuerpos normativos en materia de integración social y urbana.

69 Ver Orfield (2005), Massey et al. (2013)
} 


\section{BIBLIOGRAFÍA CITADA}

Agostini, Claudio, Hojman, Daniel, Román, Alonso y Valenzuela, Luis (2016): "Segregación residencial de ingresos en el Gran Santiago, 1992-2002: una estimación robusta", Revista de Estudios Urbano Regionales (EURE), vol. 42, No 127: pp. 159-184.

BАвСоск, Richard F. (1966): The Zoning Game: Municipal Practices and Policies (Madison, University of Wisconsin Press).

Baldwin, Robert, Cave, Martin y Lodge Martin (2012): Understanding Regulation: Theory, Strategy, and Practice (Oxford, Oxford University Press)

Been, Vicki (2005): "Residential Segregation: Vouchers and Local Government Monopolists", Yale Law \& Policy Review, vol. 23, No 1: pp. 33-39.

Been, Vicki, Madar, Josiah y McDonnell, Simon (2014): "Urban Land-Use Regulation: Are Homevoters Overtaking the Growth Machine?", Journal of Empirical Legal Studies, vol. 11, No 2: pp. 227-265.

Cashin, Sheryll D (1999): "Localism, Self-Interest, and the Tyranny of the Favored Quarter: Addressing the Barriers to New Regionalism", The Georgetown Law Journal, vol. 88: pp. 1985-2048.

Chetty, Raj, Hendren, Nathaniel y Katz, Lawrence F. (2016): “The effects of exposure to better neighborhoods on children: New evidence from the Moving to Opportunity experiment", American Economic Review, 106, No 4: pp. 855-902.

CarCeller, Antonio (1992). Introducción al derecho urbanistico (Madrid, Editorial Tecnos).

Centro de Políticas Públicas UC (2010): "Logros y dificultades que enfrentan los proyectos inmobiliarios que promueven la mezcla social de familias de distintos ingresos": Disponible en: https://politicaspublicas.uc.cl/wp-content/uploads/2015/02/descargariv-ciclo.pdf. Fecha de consulta: 14 de noviembre de 2020.

Cordero, Eduardo (2015): "Naturaleza, Contenido y Principios del Derecho Urbanístico Chileno", Revista de Derecho Universidad Católica del Norte, Año 22, No 2: pp. 93-138.

Cordero, Eduardo (2017): "La formación del Derecho urbanístico chileno a partir del siglo XIX: de la legislación urbanística al Derecho urbanístico integrado", Revista de Derecho (Valdivia), vol. XXX, No 1: pp. 127-152.

Echenique, Juan y UrzúA, Sergio (2013): “Desigualdad, Segregación y Resultados Educacionales. Evidencia desde el Metro de Santiago", Puntos de Referencia, Centro de Estudios Públicos, No 359: pp. 1-13.

Fischel, William A. (2001): The Homevoter Hypothesis (Cambridge, Mass., Harvard University Press).

FORD, Richard Thompson (1994): "Boundaries of Race: Political Geography in Legal Analysis", Harvard Law Review, vol. 107, No 108: pp. 1841-1921.

Friedman, Lawrence M. (1966): "Public housing and the poor: an overview", California Law Review, vol. 54: pp. 642-669.

Friedman, Lawrence M. (1986): “The Law and Society Movement”, Stanford Law Review, vol. 38: pp. 763-780.

FRUG, Gerald E (2001): City making: Building communities without building walls (Princeton N. J., Princeton University Press). 
Gil Mc CaWley, Diego (2019): "Law and Inclusive Urban Development: Lessons from Chile's Enabling Markets Housing Policy Regime", American Journal of Comparative Law, vol. 67, Issue 3: pp. 587-636.

Grandon, Mario y Astaburuaga, José (2017): “Desarrollos en Vivienda Social”, en Simian, José Miguel y NikLitscheK, Verónica (edit.), La Industria Inmobiliaria en Chile: Evolución, Desafíos y Mejores Prácticas (Lima, Pearson) pp. 415-440.

Larrañaga, Osvaldo y Sanhueza, Claudia (2007): "Residential Segregation Effects on Poor's Opportunities in Chile", Serie Documentos de Trabajo, Departamento de Economía de la Universidad de Chile, Working Paper No 259. Disponible en: http://repositorio.uchile.cl/bitstream/handle/2250/144350/Residential-Segregation. pdf?sequence=1 1 is Allowed=y. Fecha de consulta: 14 de noviembre de 2020.

Massey, Douglas S. y Denton, Nancy A. (1993): American apartheid: Segregation and the making of the underclass (Cambridge, Mass., Harvard University Press).

Massey, Douglas S., Albright, Len, Casciano, Rebecca, Derickson, Elizabeth y Kinsey, David N. (2013): Climbing Mount Laurel: The struggle for affordable housing and social mobility in an American suburb (Princeton N. J., Princeton University Press).

Ministerio de Desarrollo Social: "Observatorio Social". Disponible en: http://observatorio.ministeriodesarrollosocial.gob.cl/casen/casen_def_vivienda.php. Fecha de consulta: 28 de mayo de 2019.

Ministerio de Vivienda y Urbanismo: "Proveedores Técnicos MiNVU”. Disponible en: http://proveedorestecnicos.minvu.gob.cl/entidades-patrocinantes/. Fecha de consulta: 28 de mayo de 2019.

Ministerio de Vivienda y Urbanismo (2014): "Hacia una Nueva Política Urbana para Chile, Política Nacional de Desarrollo Urbano”. Disponible en: http://cndu.gob.cl/wpcontent/uploads/2014/10/L4-Politica-Nacional-Urbana.pdf. Fecha de consulta: 11 de noviembre de 2018.

OECD (2013): “OECD Urban Policy Reviews: Chile”. Disponible en: http://www. oecd-ilibrary.org/urban-rural-and-regional-development/oecd-urban-policy-reviewschile-2013_9789264191808-en. Fecha de consulta: 11 de noviembre de 2017.

Orfield, Myron (2005): "Land use and housing policies to reduce concentrated poverty and racial segregation", Fordham Urban Law Journal, vol. 33, No 3: pp. 877-936.

Ponce, Julí (2002): Poder Local y Guetos Urbanos. Las relaciones entre el Derecho Urbanistico, la Segregación Espacial y la Sostenibilidad Social (Madrid, INAP).

Rajevic, Enrique (2000): "Derecho y legislación urbanística en Chile", Revista Derecho Administrativo Económico, vol. 2, No 2: pp. 527-548.

Rajevic, Enrique (2010a): "Cohesión Social e Intervención Administrativa en el Territorio Urbano (con especial referencia a España y Chile)”. (No publicado).

RAJEVIC, Enrique (2010b): "El paulatino pero insuficiente desarrollo del derecho urbanístico en Chile: en tránsito de la adolescencia a la madurez", Fórum de Direito Urbano e Ambiental, Año 1, No 1: pp. 61-70.

RajeVIC, Enrique (2013): "La privatización de las funciones públicas en el urbanismo y la vivienda”, en Vergara, Alejandro y Bocksang, Gabriel (edit.), Público y Privado en 
Derecho Administrativo. Actas de las VIII Jornadas de Derecho Administrativo (Santiago, LegalPublishing) pp. 221-256.

Sabatini, Francisco, CáCeres, Gonzalo y Cerda, Jorge (2001): "Segregación residencial en las principales ciudades chilenas: tendencias de las tres últimas décadas y posibles cursos de acción”, Revista de Estudios Urbano Regionales (EURE), vol. XXVIII, No 82: pp. 21-42.

Sabatini, Francisco y Wormald, Guillermo (2013): "Segregación de la vivienda social: reducción de oportunidades, pérdida de cohesión”, en Sabatini, Francisco, Wormald, Guillermo y RASSE, Alejandra (edit.), Segregación de la vivienda social: ocho conjuntos en Santiago, Concepción y Talca (Santiago, Colección Estudios Urbanos UC) pp. 12-31.

Sampson, Robert J. (2012): Great American city: Chicago and the enduring neighborhood effect (Chicago, University of Chicago Press).

SAlCEDO, Rodrigo (2010): "The last slum: Moving from illegal settlements to subsidized home ownership in Chile", Urban Affairs Review, vol. 46, No 1: 90-118.

Schill, Michael y Wachter, Susan M. (1995): "Spatial Bias of Federal Housing Law and Policy: Concentrated Poverty in Urban America”, University of Pennsylvania Law Review, vol. 143, No 5: pp. 1285-1342.

SchleICHER, David (2010): "The City as Law and Economic Subject", University of Illinois Law Review, vol. 2010, No 5: pp. 1507-1563.

Schuck, Peter H. (2003): Diversity in America: Keeping government at a safe distance (Harvard University Press).

Sierra, Lucas (2006): "Urbanismo por decreto: centralismo y confusión institucional en la ciudad chilena”, en Galetovic Alexander (edit.), Santiago. Dónde estamos y hacia dónde vamos (Santiago, Centro de Estudios Públicos) pp. 301-328.

Sierralta, Carlos (2008), Efectos de la segregación residencial socioeconómica en los jóvenes de extracción popular en Santiago de Chile (1992-2002), Tesis presentada al Instituto de Estudios Urbanos y Territoriales de la Pontificia Universidad Católica de Chile para optar al Grado Académico de Magíster en Desarrollo Urbano.

WiLson, William Julius (1987): The truly disadvantaged: The inner city, the underclass, and public policy (Chicago, University of Chicago Press).

\section{NORMAS CITADAS}

Chile, Constitución Política de la República (11/8/1980).

Chile, DFL No 2 (31/7/1959), Plan Habitacional.

Chile, Ley No 16.391 (16/12/1965), Ley que crea el Ministerio de la Vivienda y Urbanismo.

Chile, DL No 1305 (19/2/1976), Reestructura y Regionaliza el Ministerio de la Vivienda y Urbanismo.

Chile, DFL No 458 (13/3/1976), Ley General de Urbanismo y Construcciones.

Chile, Ley No 18.695 (31/3/1988), Ley Orgánica Constitucional de Municipalidades.

Chile, Decreto No 47 del Ministerio de Vivienda y Urbanismo (5/6/1992), Ordenanza General de la Ley General de Urbanismo y Construcciones.

Chile, Decreto No 829 del Ministerio de Interior (11/5/1998), Reglamento Programa Mejoramiento de Barrios. 
Chile, Decreto No 116 del Ministerio de Vivienda y Urbanismo (7/2/2015), Reglamenta Subsidio Habitacional Extraordinario para Proyectos de Integración Social.

Chile, Decreto Alcaldicio No 4184 de la Iltre. Municipalidad de Maipú (11/11/2016). Disponible en http://sgd.smc.cl/MESA/BajarImagen.aspx?idimg=1097682. Fecha de consulta: 28 de mayo de 2019.

Chile, Decreto No 19 del Ministerio de Vivienda y Urbanismo (14/7/2016), Reglamenta Programa de Integración Social y Territorial, y Modifica DS No 1 (V. Y U.), de 2011, Reglamento del Sistema Integrado de Subsidio Habitacional.

\section{JURISPRUDENCIA CITADA}

Nacif con Municipalidad Peñalolén (2018): Corte Suprema (Tercera Sala), 15 de mayo de 2018. Rol No 45.353-2017.

\section{NOTAS DE PRENSA CITADAS}

El Mercurio de Santiago (6/5/2018) p. D 11.

EMOL (11/12/2011a) Disponible en: https://www.emol.com/noticias/nacio$\mathrm{nal} / 2011 / 12 / 11 / 516584 /$ comienza-plebiscito-por-plan-regulador-en-la-comuna-depenalolen.html.

EMOL (11/12/2011b) Disponible en: https:/www.emol.com/noticias/nacional/2011/12/11/516628/vecinos-de-penalolen-rechazan-modificacion-a-plan-reguladorde-la-comuna-en-inedito-plebiscito.html.

EMOL (5/7/2018) Disponible en: https://www.emol.com/noticias/Nacional/2018/07/05/912198/Viviendas-sociales-en-la-rotonda-Atenas-Radiografia-a-la-ubicacion-del-proyecto-anunciado-por-Lavin.html.

EMOL (14/7/2018) Disponible en: https://www.emol.com/noticias/Nacional/2018/07/13/913286/Alcaldesa-de-Penalolen-y-conflicto-por-viviendas-sociales-Sedisfraza-de-medioambiental-un-acto-abierto-de-discriminacion.html.

La Tercera PM (10/4/2018) Disponible en: https://www.latercera.com/la-tercera-pm/noticia/escala-pelea-lavin-torrealba-gobierno-entra-mediador-integracion-social/128932/.

Radio U. De Chile (12/12/2011) Disponible en: https://radio.uchile.cl/2011/12/12/plebiscito-comunal-en-penalolen-rechaza-cambios-al-plan-regulador-impulsados-por-alcaldeorrego/. 
